EPJ Web of Conferences 98, 03001 (2015)

DOI: 10.1051/epjconf/20159803001

(C) Owned by the authors, published by EDP Sciences - SIF, 2015

\title{
Oil shale, shale oil, shale gas and non-conventional hydrocarbons
}

\author{
A. $\operatorname{Clerici}(*)$ \\ WEC World Resources and CESI - Milano, Italy \\ G. $\operatorname{Alimonti}(* *)$ \\ INFN and Università degli Studi - Milano, Italy
}

\begin{abstract}
Summary. - In recent years there has been a world "revolution" in the field of unconventional hydrocarbon reserves, which goes by the name of "shale gas", gas contained inside clay sediments micropores. Shale gas finds particular development in the United States, which are now independent of imports and see a price reduction to less than one third of that in Europe. With the high oil prices, in addition to the non-conventional gas also "oil shales" (fine-grained sedimentary rocks that contain a large amount of organic material to be used both to be directly burned or to extract liquid fuels which go under the name of shale oil), extra heavy oils and bitumen are becoming an industrial reality. Both unconventional gas and oil reserves far exceed in the world the conventional oil and gas reserves, subverting the theory of fossil fuels scarcity. Values and location of these new fossil reserves in different countries and their production by comparison with conventional resources are presented. In view of the clear advantages of unconventional fossil resources, the potential environmental risks associated with their extraction and processing are also highlighted.
\end{abstract}

${ }^{*}$ ) Chair of the WEC Study Group on "Global Energy Resources and Technologies" and Senior Advisor CESI.

$\left.{ }^{* *}\right)$ Member of the EPS Energy Group.

This is an Open Access article distributed under the terms of the Creative Commons Attribution License 4.0, which permits unrestricted use, distribution, and reproduction in any medium, provided the original work is properly cited. 


\section{EPJ Web of Conferences}

\section{1. - Introduction}

In recent years the global energy sector has witnessed a "revolution" led by the United States that goes by the name of "shale gas"; such a "revolution" passed up to few time ago quite unnoticed in Italy, linked to gas imports through pipelines with long-term contracts.

The United States now get more than $25 \%$ of their consumption from the "shale gas" and have become independent of large imports of the expensive LNG (liquefied natural gas); US are already planning for the near future to become exporters of LNG and some supply contracts for 2016 seem to have already been defined. But what is shale gas and how does it rank among the non-conventional fuels?

Many of the data reported in this article refer to the WEC publications [1-3] with updates derived from meetings with experts during WEC workshops.

\section{2. - Few definitions for non-conventional hydrocarbons}

We define "oil shales" those fine-grained sedimentary rocks that contain a large amount of organic material (kerosen); they can be used to be directly burned as fuel (e.g. Estonia still produces almost all of its electricity from oil shale burned in special boilers) or to extract liquid fuels (oil shale) or partly gaseous. In the oil shale the ratio of organic matter $(\mathrm{OM})$ and mineral material (MM) can vary from 7.1 to 3.1; the organic material decomposes at about $500{ }^{\circ} \mathrm{C}$ in shale oil and gas.

The coal differs from oil shale by having a lower hydrogen/carbon ratio but a OM/MM ratio almost equal to 1 .

The use of the oil shale can be traced back to 1600 and since 1950 about 20 million to 45 million tons per year have been extracted (see fig. 1) for the most part in Estonia and much smaller quantities in Russia, China and Brazil. Scotland had been the largest and practically single producer until 1935 .

Since the shale oil content is about $100 \mathrm{l} /$ ton of oil shale, its low use to derive oil was mainly due to the lower cost of conventional oil.

Extra heavy oils and the bitumen are contained in deposits of oil that have been degraded over time for microbiological action and have reached a density greater than that of the conventional petroleum (1:02 to 1:04 compared to 0.83) and a remarkable viscosity (1000 times higher than that of oil for extra-heavy oils and 30000 times higher for the bitumen). They contain a greater proportion of metals such as nickel and vanadium, sulfur and nitrogen compared to oil.

The extra-heavy oils are found in deposits ranging from hundreds of meters depth (China, Poland, Indonesia) to 1500 meters (Venezuela, Russia, UK, Israel) or up to 3000 meters in Peru.

The bitumen is contained in rocks commonly called "tar sands" or "oil sands" and has been used since antiquity for flooring; the depth of the deposits varies from a few meters (China and Madagascar) to 350 meters (Canada).

The extraction and upgrading of extra-heavy oils and bitumen for transport and processing into finished products includes various types of interventions, where water, 


\section{LNES 2014}

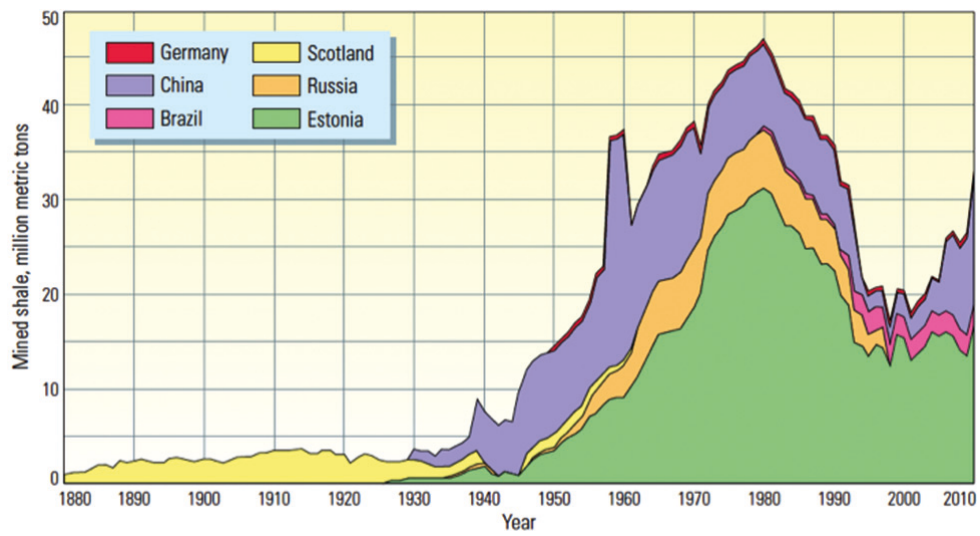

Fig. 1. - Oil shale world production. Source: Pierre Allix, Alan K. Burnhan et al.

heat, solvents and different processes are used to increase the hydrogen/carbon ratio ("carbon rejection" or "hydrogen addition") depending both on the type of available "raw material" and on the finished products to be obtained.

Shale gas is natural gas contained free in clay sediments micropores (fig. 2) or "attacked" to their surface; deposits are located between 2000 and 5000 meters deep, and its extraction is carried out with vertical and then horizontal drilling (fig. 3) using highpressure water ("hydraulic fracturing") with chemical additives to promote leakage of the gas and "channel it" to the surface.

Only about $25 \%$ of the introduced water returns to the surface where, to be recycled, it requires a special treatment.

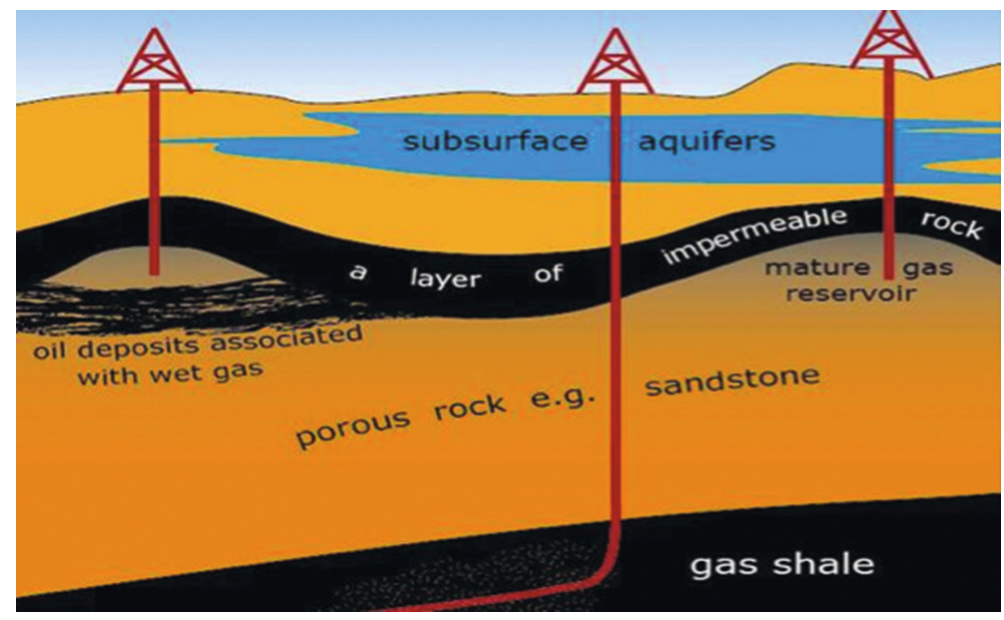

Fig. 2. - Deposits of shale gas. 


\section{EPJ Web of Conferences}

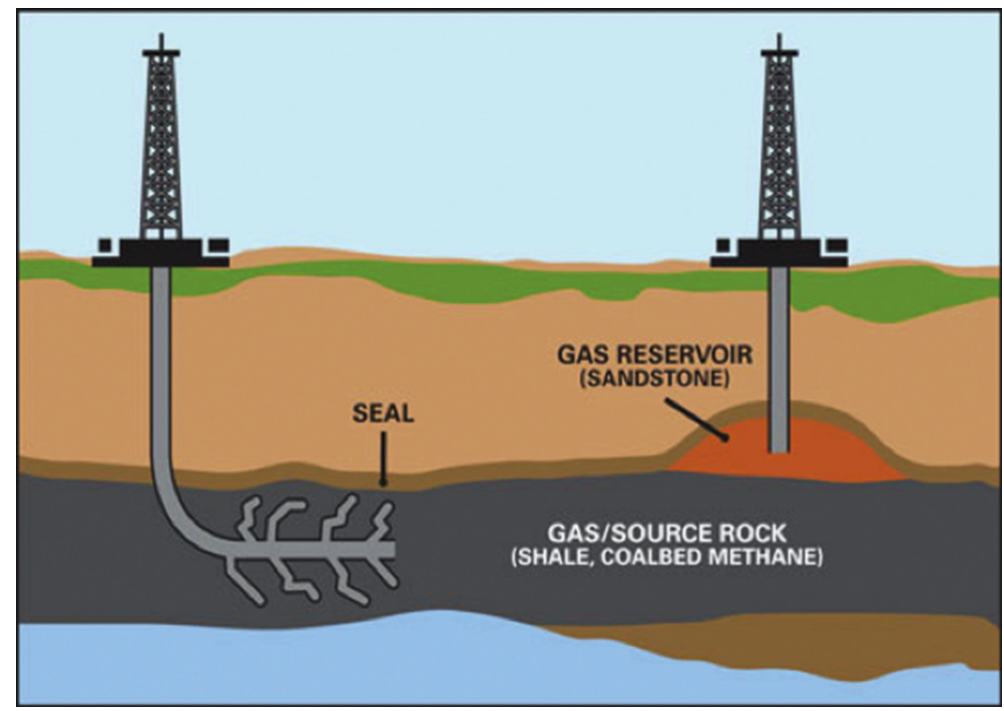

Fig. 3. - Technology for shale gas extraction.

Another technology under study provides the "gas fracturing" with liquefied propane with water savings and reduced danger of contamination.

The recovery of the gas contained in a reservoir is currently around $30 \%$ with the need to drill a large number of wells to obtain an economically viable production.

\section{3. - The reserves of unconventional hydrocarbons}

World reserves of oil shale are estimated to be around 660 billion TOE (tons of oil equivalent) content of shale oil and $30 \%$ of these are technically extractable; they are therefore superior to the 175 billion TOE of proven reserves of conventional oil.

About $2 / 3$ of the reserves are in the United States, followed by Russia and Brazil, which together have a share of $20 \%$.

The shale oil production from oil shale is now about 1 million tons per year, compared to about 4 billion tons of conventional oil.

The proven reserves of bitumen are measured with a content of extractable oil of 35 billion TOE, $70 \%$ of those are in Canada, followed by Kazakhstan and Russia. The estimated 598 deposits in 23 countries, potentially contain more than 300 billion TOE of oil. The current world production from tar sands/bitumen comes almost solely from Canada and it is about 65 million TOE per year, which corresponds to $45 \%$ of the total oil production from Canada.

The proven reserves of extra-heavy oils contain recoverable oil for about 75 billion TOE and more than 70 billion of those are in Venezuela. The production is about 50 million tons per year, almost exclusively in Venezuela. The deposits identified in 30 countries potentially contain oil equal to about 50 times the proven reserves and also the greatest potential are in the "Orinoco Belt" in Venezuela. 


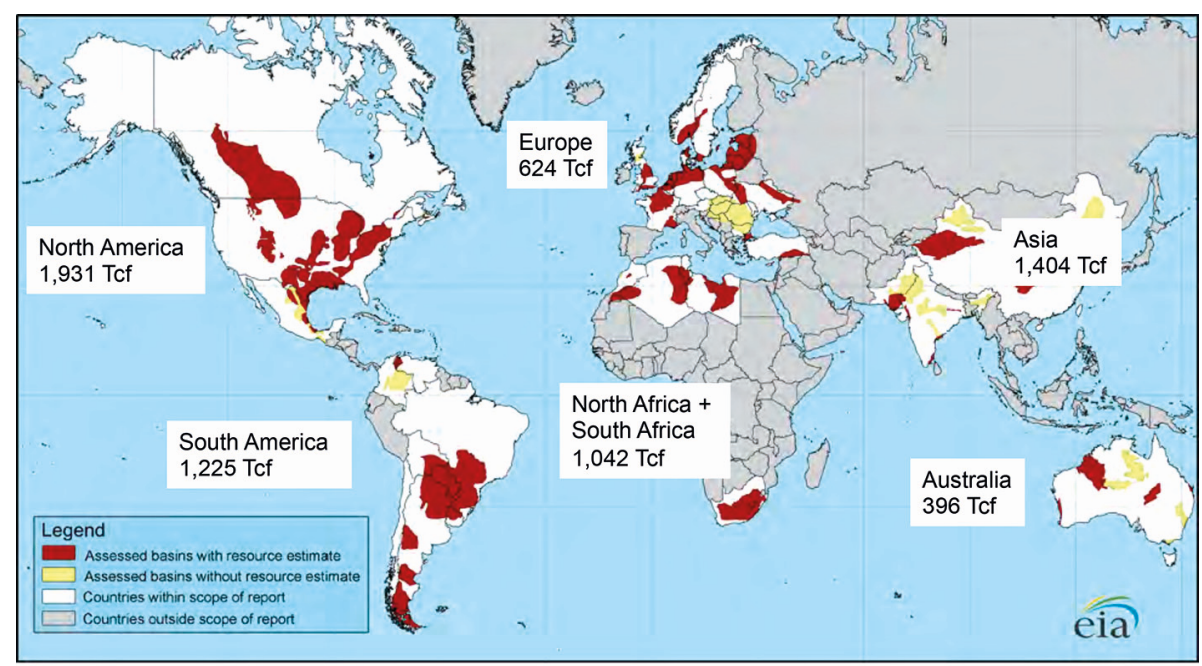

Source: EIA/ARI World Shale Gas Resources, 2011

Fig. 4. - World "risked" recoverable shale gas estimates 2011.

The shale gas "risked" global resources are approximately 200 trillion $\mathrm{m}^{3}$ divided into 48 basins in 32 countries, without counting the Central Africa countries as well as Russia and the Middle East that possess large reserves of natural gas.

Although estimates vary frequently according to new findings, a breakdown by continents would be (see fig. 4):

$\begin{array}{ll}\text { North America } & \sim 29 \%, \\ \text { Asia } & \sim 22 \%, \\ \text { South America } & \sim 19 \%, \\ \text { North Africa and South Africa } & \sim 15 \%, \\ \text { Europe (no Russia) } & \sim 9 \%, \\ \text { Australia } & \sim 6 \% .\end{array}$

China is the first country with $18 \%$ of the probable reserves followed by United States, Argentina and Mexico.

With regard to Europe, Poland is the country with the highest "recovery risked resources" equal to 5 trillion $\mathrm{m}^{3}$ closely followed by France, Norway, Ukraine, Sweden, Denmark, UK, Germany and the Netherlands, as shown in figs. 5 and 6 .

Shale gas world reserves are estimated to be more than 2.5 times the natural gas reserves, bringing the ratio between reserves and current gas consumption to well over 200 years.

Shale gas world production is practically confined to the States that in 2012 have passed 175 billion $\mathrm{m}^{3}$ (twice the number of Italian annual gas consumption). 


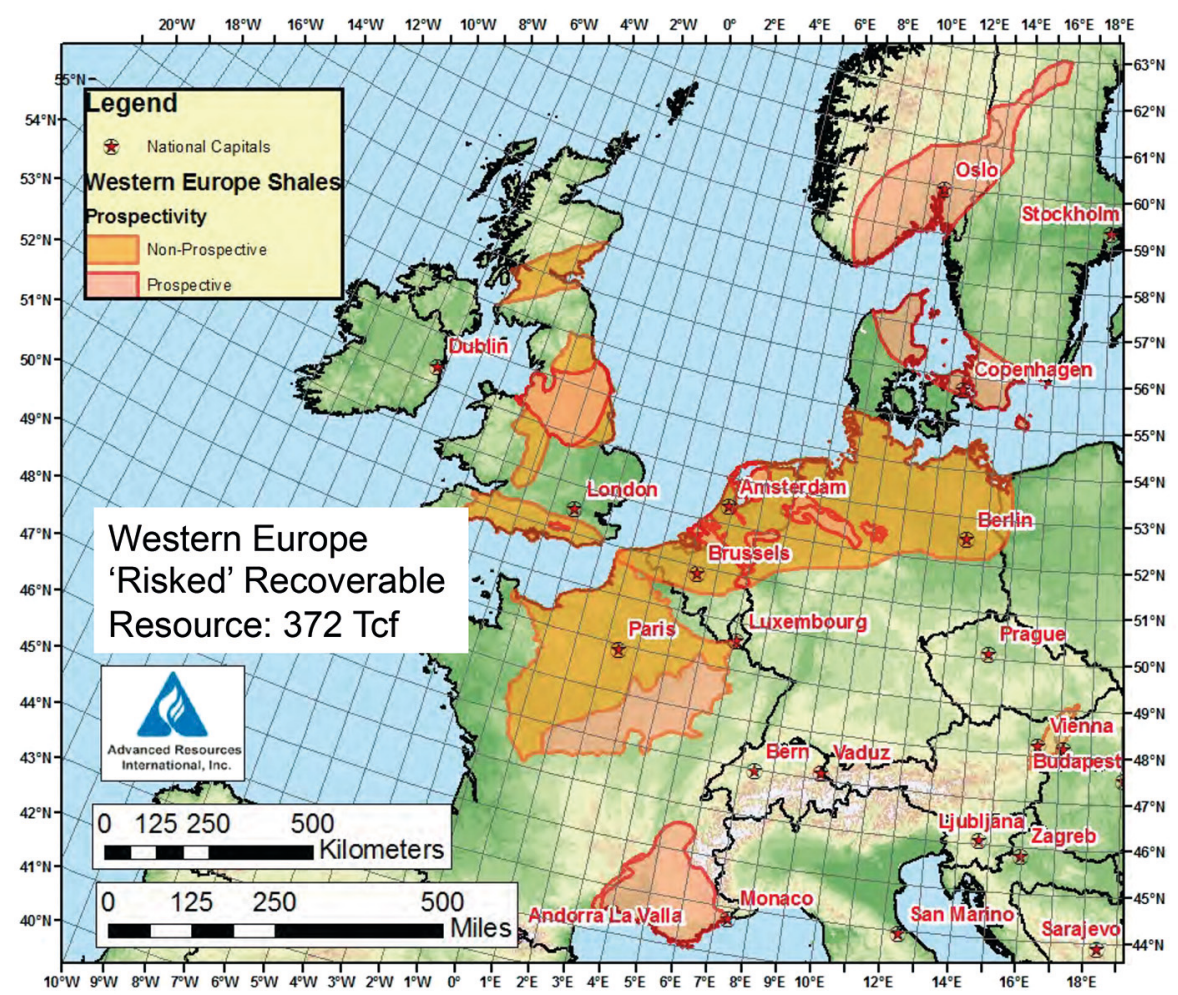

Source: EIA/ARI World Shale Gas Resources, 2011

Fig. 5. - Western Europe "risked" recoverable shale gas estimates 2011.

\section{4. - Shale gas: opportunities, risks, and geopolitical aspects}

The potentially great shale gas resources mentioned above with the recent years rapid development in the United States, have marked and are strongly influencing the current and future energy scenario.

It is worth mentioning that in the United States (basically today the only large shale gas producers in the world) the production has gone from of 59 billion $\mathrm{m}^{3}$ in 2008 to over 175 billion $\mathrm{m}^{3}$ in 2012 , with a $25 \%$ coverage from shale gas on the total consumption (with more than 30000 wells in operation) and with a projected $46 \%$ percentage by 2030 .

Such a gas supply in the market has brought the natural gas price at about $3 \$ /$ MBTU, less than one third of the gas price in Europe and less than one fifth of the price in Japan.

Gas is then dramatically increasing its share in the United States in the electricity production at the expense of coal, has virtually "killed" nuclear power - which has a cost per kWh certainly not comparable with the cost from gas-fired plants ( $\sim 3.5 \mathrm{c} \$$ per $\mathrm{kWh})$ and finally is putting serious problems for the competitiveness of renewable resources. 


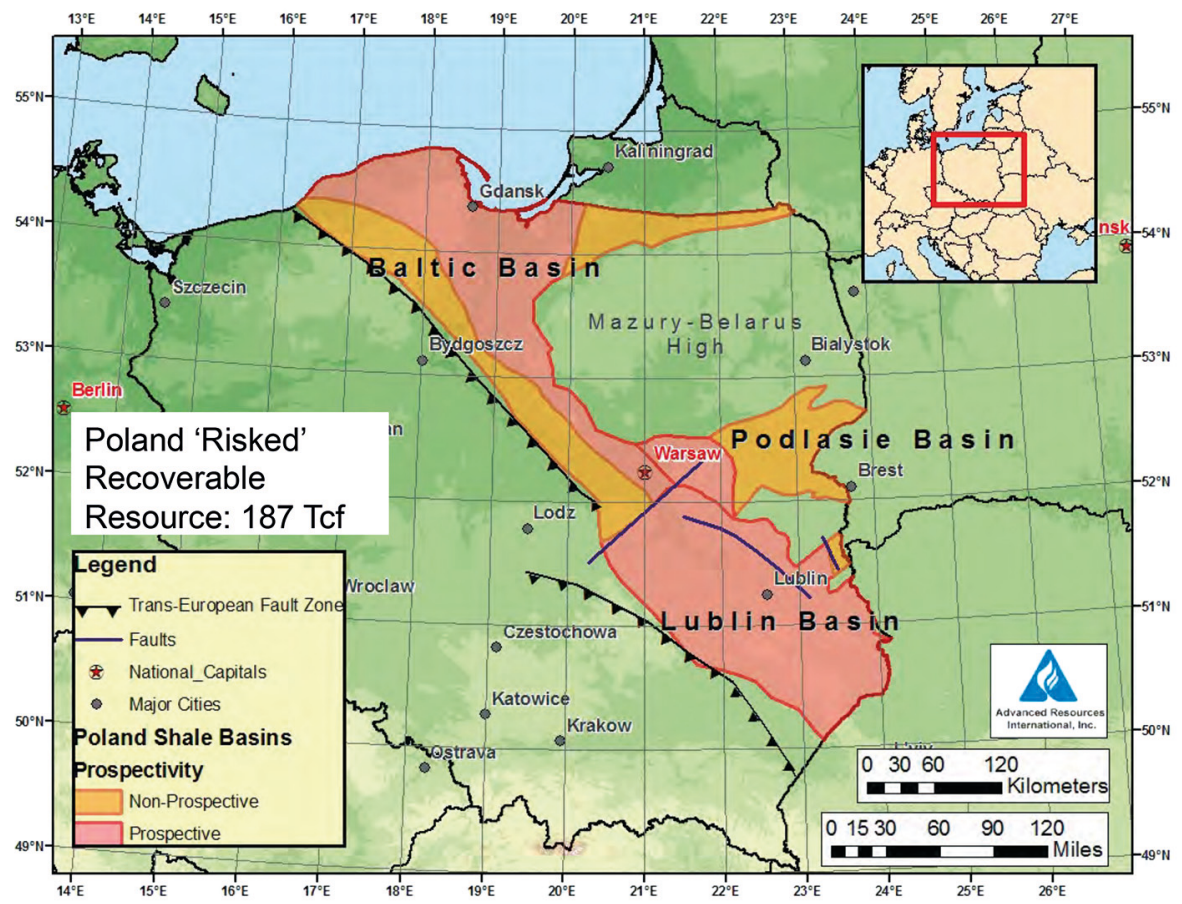

Source: EIA/ARI World Shale Gas Resources, 2011

Fig. 6. - Poland "risked" recoverable shale gas estimates 2011.

The reduction of coal consumption in the United States has led to a strong US coal export in the global market, influencing its prices.

In the WEC Energy Leaders Forum in February 2013 in New Delhi, it has been pointed out that the local gas consumption at a low price in the United States is addressed to the substitution of coal for electricity production. The gas has seen its share in the electricity production rising from $16 \%$ in 2000 to $32 \%$ in 2012 and it was expected at about $33 \%$ in 2013 but in reality went down to $28 \%$ against a coal share decline from $52 \%$ in 2000 to $36 \%$ in 2012 but up to $39 \%$ in 2013 . The possible exporting volumes are not predictable but not such to contribute to a substantial alignment of the world gas prices, considering the costs associated with liquefaction-gasification-shipping. In any case, the United States plan to export not only LNG, but products derived from gas. In 2010 over 800000 jobs were estimated directly and indirectly associated with the development of shale gas which, however, is placing several problems at the political, industrial, economic and environmental level.

As far as the shale gas price/cost, the price is artificially low compared to the production cost being tied to profits related to "precious fluids" associated with the gas extraction; moreover research/exploitation of new deposits is oriented towards those fields with high content of fine associated liquids. It was emphasized that a correct price 


\section{EPJ Web of Conferences}

would be around 6-7 \$/MBTU and this value will be reached as soon as the gas share has further reduced the coal share.

A further increase in the shale gas production is driven both by investors and by the plant industry linked both to the construction of large liquefaction plants for gas export and to plants to turn gas into finished products.

There is also a push for the use of gas as a "green" transitional stage in transportation between petrol cars and electric vehicles.

Interest groups mentioned above also push towards a massive gas export bearer of good margins, given the high prices in other areas.

This export is instead seen by some as a threat to the energy security of the United States and for the inevitable increase in local gas prices.

Others argue that a massive LNG export from the United States to Europe at a good price, would create major economic problems to the "ally/enemy" Russia, the main gas supplier to Europe; this would lead Europe to ease its energy bills and bring it back more tied to the United States.

In any case, the energy flows that saw large LNG transfers to the United States stopped and they are foreseen, as mentioned above, to be reversed in the coming years. On the other end, coal that loses its share in the United States, is having an increased outflow.

In any case, the shale gas revolution is bringing substantial benefits to the United States:

- increase in industrial activity and employment;

- improving the balance of payments;

- low costs especially for electricity and resulting increase in competitiveness compared to an European Union that is going towards an higher energy cost for end users, also caused by heavy taxes and renewable energy commitments for $\mathrm{CO}_{2}$;

- reduction of environmental impact; the electricity production by gas combined cycles emits $40 \%$ of the $\mathrm{CO}_{2}$ emitted by coal electricity production and the possible use of gas for transportation would reduce traction emissions compared to gasolin cars.

Despite all of the above, there are potential risks basically related to environmental issues that are here below summarized.

It should be reminded that the shale gas extraction has significant environmental impacts repeatedly stressed by environmental movements. In particular:

- possible micro-earthquakes as a result of fractures in underground layers;

- leakage into the atmosphere of methane gas, which has by far a larger greenhouse effect than $\mathrm{CO}_{2}$;

- pollution of aquifers by injection both of methane and of the used solvents; 


\section{LNES 2014}

- large water volumes injected that return to the surface for only $25 \%$ with problems coming from particular treatments needed before being re-injected;

- great and "mobile" land surface occupation.

Companies involved in shale gas extraction reply to these objections that:

- the solvents are only $0.5 \%$ of the injected water volume and they are not harmful to the aquifers that are located thousands of meters above the shale gas deposits;

- the used hydraulic fracturing cannot cause seismic movements;

- the gas leakage in the atmosphere and in the soil is practically nothing, thanks to the sophisticated used technologies that are in constant evolution;

- the occupation of the surface land is made in full agreement with peoples and institutions.

In any case, a greater transparency of methods and used substances seems essential to arrive at a shared acceptability.

It should be emphasized that just an emotional reaction of the populations acknowledged at the political level with restrictive laws, could block the deposits exploitation, as already happened in some countries, or greatly affect the cost of shale gas, then resizing the anticipated developments. It is worth mentioning that France and Bulgaria have banned the "hydraulic fracturing" and also Quebec in Canada is imposing severe restrictions.

\section{5. - Concluding remarks on fossil fuels}

The proven reserves of conventional fossil fuels $(R)$ compared to the current annual production $(P)$ have a $R / P$ ratio equal to

- 120 years for coal,

- 60 years for conventional natural gas,

- 56 years for conventional oil.

The unconventional oil and gas reserves were evaluated more and more closely and reached a huge potential but have not been exploited due to their higher cost compared to conventional sources, especially oil. However, with the oil cost to $\$ 100 /$ barrel in the last period and with the shale gas revolution, maybe not convenient in itself, but when paired with the convenient "precious liquids" associated in its extraction, the situation is changing, particularly concerning the shale gas sector where the United States are the champions and where its entry into the market has brought down the gas price to local unthinkable values. 


\section{EPJ Web of Conferences}

The investments to extract unconventional oil are impressive but with an oil market value stable at around 90-100 dollars a barrel for several years, they have a more than positive return.

In conclusion, considering both conventional and non-conventional fossil fuels, at current consumption rates we have resources of coal, oil and gas for over 200 years and the progress of technology (40 years ago it was said that there was oil for only 40 years) will extend these durations.

The general problem is not therefore the scarcity of resources (fear to be dispelled), but how to extract and to transform them in an environment compatible manner; there is much to be done to optimize the technologies and the suggestion is to have non-ideological approaches but great transparency on methodologies and adopted "additives" and a clear assessment of risks.

\section{REFERENCES}

[1] WeC-World Energy Council, Survey of Energy Resources, 22nd edition, 2010.

[2] WeC-World Energy Council, Survey of Energy Resources: Focus on Shale Gas, 2010.

[3] WeC-World Energy Council, Survey of Energy Resources: Shale Gas-What's New, 2012. 